\title{
Continuum of hepatitis $C$ care cascade in prison and following release in the direct-acting antivirals era
}

\author{
Sanam Hariri ${ }^{1 \dagger}$, Heidar Sharafi ${ }^{2 \dagger}$, Mahdi Sheikh ${ }^{3,1}$, Shahin Merat ${ }^{1}$, Farnaz Hashemi ${ }^{1}$, Fatemeh Azimian ${ }^{4}$, \\ Babak Tamadoni ${ }^{5}$, Rashid Ramazani ${ }^{4}$, Mohammad Mehdi Gouya ${ }^{4}$, Behzad Abbasi ${ }^{1}$, Mehrzad Tashakorian", \\ Ramin Alasvand ${ }^{5}$, Seyed Moayed Alavian², Hossein Poustchi ${ }^{*}$ (D) and Reza Malekzadeh ${ }^{1}$
}

\begin{abstract}
Background: People with criminal justice involvement contribute remarkably to the rising hepatitis C virus (HCV) burden; however, the continuum of care is a major barrier to prison-based programs. We aimed to evaluate a comprehensive HCV care model in an Iranian provincial prison.

Methods: Between 2017-2018, in the Karaj Central Prison, newly admitted male inmates received HCV antibody testing and venipuncture for RNA testing (antibody-positive only). Participants with positive RNA underwent directacting antiviral (DAA) therapy (Sofosbuvir/Daclatasvir). Sustained virological response was evaluated at 12 weeks post-treatment (SVR12).

Results: Overall, from 3485 participants, 182 (5.2\%) and 117 (3.4\%) tested positive for HCV antibody and RNA, respectively. Among 116 patients who were eligible for treatment, 24\% $(n=28)$ were released before treatment and $72 \%(n$ $=83)$ initiated DAA therapy, of whom $81 \%(n=67 / 83)$ completed treatment in prison, and the rest were released. Of total released patients, $68 \%(n=30 / 44)$ were linked to care in community, and $70 \%(n=21 / 30)$ completed treatment, including 60\% $(n=12 / 20)$ and 90\% $(n=9 / 10)$ among those who were released before and during treatment, respectively. The overall HCV treatment uptake and completion were 89\% $(n=103 / 116)$ and 85\% $(n=88 / 103)$, respectively. From people who completed treatment, $43 \%(n=38 / 88)$ attended for response assessment and all were cured $(\mathrm{SVR} 12=100 \%)$.

Conclusions: Integrated HCV care models are highly effective and can be significantly strengthened by post-release interventions. The close collaboration of community and prison healthcare systems is crucial to promote high levels of treatment adherence. Future studies should investigate the predictors of engagement with $\mathrm{HCV}$ care following release.
\end{abstract}

Keywords: Hepatitis C virus (HCV), HCV treatment, Linkage to care, Prison healthcare, Harm reduction, HCV elimination

\footnotetext{
*Correspondence: h.poustchi@gmail.com

tSanam Hariri and Heidar Sharafi should be considered joint first authors ${ }^{1}$ Liver and Pancreatobiliary Diseases Research Center, Digestive Disease Research Institute, Shariati Hospital, Tehran University of Medical Sciences, N. Kargar St., 14117 Tehran, Iran

Full list of author information is available at the end of the article
}

\section{Background}

Following the introduction of highly effective antiviral agents, the hepatitis $\mathrm{C}$ virus (HCV) infection has become curable in the recent decade [1]; hence treatment of infected people has been introduced as a key strategy for disease prevention in communities [2]. Imprisonment and the increased risk of transmission after 
release remarkably contribute to the rising $\mathrm{HCV}$ burden worldwide [3, 4]. Accordingly, many countries are scaling up prison-based programs to reach the World Health Organization (WHO) target of viral hepatitis elimination as a public health issue by 2030 [5, 6]. A few studies have reported near- or micro-elimination of $\mathrm{HCV}$ in specific prison settings; however, evidence around the postrelease engagement with care is scarce [7].

$\mathrm{HCV}$ case-finding among the prison population who often are underserved by community healthcare services has appeared to be cost-effective [8]. Despite the encouragement brought by recent successes, many countries have challenges expanding $\mathrm{HCV}$ care among people with criminal justice involvement, and access to health services often ends with patient's release back into community $[9,10]$. Retrospective studies from the USA have shown that only $10 \%$ of formerly incarcerated patients are linked to HCV care after release $[11,12]$. Short prison sentences lead to high rates of treatment discontinuations, which highlights the necessity of ensuring care continuity upon release [13]. However, the transition period is accompanied by many competing priorities that often prevent patients from ongoing engagement with care $[9,11]$. Such priorities include inadequate social and financial support, which often result in a return to drugrelated activities and may erode all health benefits gained during incarceration $[9,14,15]$.

Lack of appropriate discharge planning for $\mathrm{HCV}$ treatment, as well as mental disorders and substance use treatment, results in difficulty navigating through community healthcare services after release $[16,17]$. Besides, poor integration between prison and community is another obstacle that can hinder immediate linkage to care and contribute to the cycle of suboptimal achievement of HCV elimination programs [18]. Communitybased organizations and NGOs can play an invaluable role in the community reintegration of offenders [19]. To date, studies on linkage to care from incarceration have been mainly focused on people with HIV infection, and a variety of strategies, including case management and patient navigation, have been introduced to facilitate the transition period for these patients [15, 20]. Although developing effective care models require knowledge on the gaps in continuity of care and potential solutions [11], evidence lack around feasibility and efficiency of such interventions among $\mathrm{HCV}$ patients [21, 22]. Community reintegration and post-release continuity of care are current priority areas for prison healthcare research [23].

To date, no study is published on the effectiveness of $\mathrm{HCV}$ interventions among people with criminal justice involvement in low- or middle-income countries [24]. In recent decades, the Iranians Prisons Organization has adopted progressive harm-reduction policies; however,
HCV screening and treatment are not yet provided routinely at correctional facilities. We aimed to implement a comprehensive $\mathrm{HCV}$ care model in a provincial prison in Iran, as a middle-income country.

\section{Methods}

\section{Study population}

This interventional study was conducted in the context of a national pilot on "Screening, diagnosis, and treatment of hepatitis C in Iranian prisons." Between June 2017 and February 2018, all newly admitted male inmates in the Central Prison of Karaj, who aged above 18 years, were recruited given providing written consent. The exclusion criteria were hepatitis $\mathrm{B}$ infection, chronic kidney disease, cirrhosis, and HIV co-infection due to the antiretroviral drug interactions. After enrollment, the study was ongoing for about two years and patients were followed by June 2019 to complete treatment and response assessment. The review board of the Digestive Diseases Research Institute of Tehran University of Medical Sciences approved the study protocol.

\section{Study site}

The Central Prison of Karaj is a large prison located in Karaj city, Alborz province, which is effectively a suburb of the capital city of Iran. This prison with 14 wardsinmates residing in 10 wards and four wards provide food and other services-is home to 6000 inmates at any given time and has approximately 30 new admissions daily; the majority are involved with drug-related charges (five out of 10 wards). A baseline behavioral survey was conducted in 2007, just before the introduction of methadone maintenance treatment (MMT) in this prison. According to that survey, the prevalence of drug use and injecting drug use was $93 \%$ and $42 \%$, respectively; participants also reported having been incarcerated an average of five times before their current prison sentence [25]. The Central Prison of Karaj has a triangular clinic with one general practitioner, one psychologist, and several nurses who provide healthcare services, including HIV testing and methadone dispensing. However, there is no HCV screening or treatment program available.

\section{Sample collection}

Before starting the project, several workshops were held by the study coordinators to educate the prison healthcare staff and ensure sampling methods. All inmates received a rapid diagnostic test (RDT) for the HCV antibody using a finger-stick blood specimen. Irrespective of the result, participants underwent venipuncture for another antibody testing by a fourth-generation enzymelinked immunosorbent assay (ELISA). Blood samples 
were transferred daily to a reference laboratory outside. In case of discordant results, the plasma sample was reevaluated by RDT in the laboratory to recognize testing errors in prison. On samples with confirmed positive antibody, quantitative HCV RNA test (The Artus HCV RG RT-PCR Kit, Qiagen) and genotyping were performed by reverse transcription-polymerase chain reaction (RTPCR) followed by sequencing [26]. Sample collection procedures have been previously detailed elsewhere [27].

\section{Treatment in prison}

All required education for treatment and monitoring were delivered by a liver specialist to the physician and nurses. The HCV coordinator in prison was responsible for receiving test results from the laboratory, confirming the accuracy of the patient's contact information, and leading those with positive HCV RNA to the triangular clinic for pre-treatment counseling and biobehavioral assessment by questionnaire. Further evaluations, including complete blood count, liver enzymes, creatinine, and hepatitis B testing, were conducted in the prison laboratory before treatment initiation. AST to Platelet Ratio Index (APRI) was used for liver disease assessment, calculated as follows: [AST (U/l)/upper limit of normal (considered as $40 \mathrm{U} / \mathrm{l}) /$ platelet count $\left.\left(10^{9} / \mathrm{l}\right)\right] \times 100$. Patients received daily treatment with one tablet of a direct-acting antiviral (DAA) that was a locally-manufactured combination of $400 \mathrm{mg}$ Sofosbuvir and $60 \mathrm{mg}$ Daclatasvir (Sovodak $^{\circledR}$, Rojan Pharma, Tehran, Iran). The duration of therapy was 12 weeks for participants without cirrhosis $(\mathrm{APRI}<2)$, and those with cirrhosis $(A P R I \geq 2)$ were referred to a specialist health center outside the prison. The prison nurses were responsible for dispensing medication through directly observed therapy (DOT) in the clinic every morning.

\section{Treatment in community}

If released during the study, patients were referred to the Alborz district health network (DHN), where several physicians and different healthcare providers are in charge. In Iran, DHN is identified as the setting responsible for providing health services at the township and rural level, under the supervision of state Universities of Medical Sciences. The prison HCV coordinator had to inform the network of patient's releases and their contact details. Five tablets were provided at the patient's disposal upon release, considering the time it takes to be linked to the network. DHN personnel were attempting to contact patients for appointment scheduling by reminder calls or reaching their residential address. Treatment was pursued by a general practitioner after receiving medical records from the prison.

\section{Study outcomes}

The study outcomes include HCV prevalence and treatment uptake. Linkage to $\mathrm{HCV}$ care, defined as a documented visit in the network, was measured among people with positive HCV RNA who released before treatment initiation or completion. The other outcome was response assessment, measured by sustained virological response 12 weeks post-treatment (SVR12). SVR12 was defined as undetectable HCV RNA, performed by PCR on the venipuncture blood samples.

\section{Statistical analysis}

Categorical variables were expressed as frequencies and percentages. The prevalence of $\mathrm{HCV}$ antibody and $\mathrm{HCV}$ RNA was calculated among all participants. Treatment uptake was measured among participants with positive HCV RNA testing, and treatment completion was evaluated among individuals who initiated treatment. Response assessment was based on intention-to-treat (ITT) among all people with positive HCV RNA who were eligible for treatment, and modified intention-totreat (mITT) that included patients who had completed treatment.

\section{Results}

Overall, 3485 newly admitted male inmates participated in the study, from whom $5.2 \%(n=182)$ tested positive for HCV antibody. The prevalence of HCV RNA among all inmates was $3.4 \%(n=117)$, indicating a viremic rate of $64 \%(n=117 / 182)$ in this prison. The most frequent genotypes were $3 \mathrm{a}$ and $1 \mathrm{a}$ with $52 \%(n=61)$ and $44 \%(n=51)$ prevalence, respectively; other genotypes included $1 \mathrm{~b}(3 \%, n=4)$ and $3 \mathrm{~h}(1 \%, n=1)$.

Questionnaire data were available for half of the participants with positive HCV RNA $(n=60)$. The median age was 38 years (interquartile range (IQR) 34-44 years); the majority were heterosexual (91\%), and had a drug-related sentence (73\%). A history of previous incarceration was reported in $63 \%$, and the mean (SD) incarceration time in the last year was 92 (147) days.

The majority had not finished high school (82\%), were not currently employed (63\%), had a minimum wage monthly income or below (65\%), and all had a history of drug use (100\%). During the last six months, one-quarter of patients had unstable housing (25\%), and the majority had lived more than half of this time with people who inject drugs (PWID) (53\%) and more than half of their friends were current drug users (67\%). Compared to all patients, those who attended SVR testing appointments were older, had higher education, 
Table 1 Characteristics of Karaj prison participants with positive HCV RNA testing

\begin{tabular}{|c|c|c|}
\hline & Total & $\begin{array}{l}\text { People } \\
\text { attended } \\
\text { SVR visit }\end{array}$ \\
\hline Characteristics, n \% & $n=60$ & $n=23$ \\
\hline Age, median (IQR) & $38(34,44)$ & $39(34,45)$ \\
\hline Male sex & $60(100 \%)$ & $23(100 \%)$ \\
\hline Drug-related sentences & $38(73.1 \%)$ & $13(61.9 \%)$ \\
\hline History of incarceration & $19(63.3 \%)$ & $7(53.8 \%)$ \\
\hline Mean incarceration days ${ }^{\dagger}$ (SD) & $92(147)$ & $114(158)$ \\
\hline \multicolumn{3}{|l|}{ Sexual orientation } \\
\hline Heterosexual & $53(91.4 \%)$ & $20(95.2 \%)$ \\
\hline Homo/bisexual & $5(8.6 \%)$ & $1(4.8 \%)$ \\
\hline \multicolumn{3}{|l|}{ Education } \\
\hline Did not finish high school & $49(81.7 \%)$ & $16(69.6 \%)$ \\
\hline Finished high school & $10(16.7 \%)$ & $7(30.4 \%)$ \\
\hline Higher education & $1(1.7 \%)$ & $0(0.0 \%)$ \\
\hline \multicolumn{3}{|l|}{ Employment } \\
\hline Unemployed & $38(63.3 \%)$ & $8(44.4 \%)$ \\
\hline Part-time & $13(21.7 \%)$ & $6(33.3 \%)$ \\
\hline Full-time & $9(15.0 \%)$ & $4(22.2 \%)$ \\
\hline \multicolumn{3}{|l|}{ Monthly income } \\
\hline Minimum wage or below & $39(65.0 \%)$ & $14(60.9 \%)$ \\
\hline Living wage & $10(16.7 \%)$ & $5(21.7 \%)$ \\
\hline Above living wage & $11(18.3 \%)$ & $4(17.4 \%)$ \\
\hline \multicolumn{3}{|l|}{ Place of residence } \\
\hline Own house & $4(8.9 \%)$ & $2(10.5 \%)$ \\
\hline Rental/Parents house & $30(66.7 \%)$ & $13(68.4 \%)$ \\
\hline Homeless & $11(24.4 \%)$ & $4(21.1 \%)$ \\
\hline \multicolumn{3}{|c|}{ Number of housings within 6 months } \\
\hline One & $43(72.9 \%)$ & $16(72.7 \%)$ \\
\hline Two or more & $15(25.4 \%)$ & $6(27.3 \%)$ \\
\hline \multicolumn{3}{|l|}{ Lived with PWID ${ }^{\ddagger}$ within 6 months } \\
\hline Never & $23(40.4 \%)$ & $10(45.5 \%)$ \\
\hline Less than half the time & $4(7.0 \%)$ & $0(0.0 \%)$ \\
\hline Half the time or more & $30(52.6 \%)$ & $12(54.6 \%)$ \\
\hline \multicolumn{3}{|l|}{ Number of friends with drug use } \\
\hline None & $10(18.2 \%)$ & $3(14.3 \%)$ \\
\hline Less than half & $8(14.6 \%)$ & $4(19.1 \%)$ \\
\hline Half or more & $37(67.3 \%)$ & $14(66.7 \%)$ \\
\hline Feeling of anxiety or depression & $46(79.3 \%)$ & $16(72.7 \%)$ \\
\hline Sense of well-being ${ }^{\S}$, mean (SD) & $63(19)$ & $68(21)$ \\
\hline
\end{tabular}

${ }^{\dagger}$ In the previous year fpeople who inject drugs

$\S$ In a scale from zero to one hundred

monthly income, and employment, and a lower proportion of them had a history of incarceration and drugrelated sentences (Table 1).
Table 2 Drug use patterns and HCV care history among Karaj prison participants with positive HCV RNA

\begin{tabular}{|c|c|c|}
\hline & Total & $\begin{array}{l}\text { People } \\
\text { attended } \\
\text { SVR visit }\end{array}$ \\
\hline Characteristics, n \% & $n=60$ & $n=23$ \\
\hline Drug use, ever & $57(100 \%)$ & $22(100 \%)$ \\
\hline Age at first drug use, median (IQR) & $18(15,22)$ & $18(16,20)$ \\
\hline Drug use within 6 months & $38(66.7 \%)$ & $16(69.6 \%)$ \\
\hline Drug use in the last month & $24(42.1 \%)$ & $9(39.1 \%)$ \\
\hline Daily use & $19(79.2 \%)$ & $7(77.8 \%)$ \\
\hline \multicolumn{3}{|l|}{ Most commonly used drugs } \\
\hline Heroine and/or Methamphetamine & $18(75.0 \%)$ & $8(88.9 \%)$ \\
\hline Methadone & $6(25.0 \%)$ & $1(11.1 \%)$ \\
\hline Injecting drug use, ever & $28(47.5 \%)$ & $11(50.0 \%$ \\
\hline Age at first injection & $20(18,25)$ & $20(18,27)$ \\
\hline Injection within 6 months & $7(25.0 \%)$ & $1(9.1 \%)$ \\
\hline Injection within the last month & $4(14.3 \%)$ & $1(9.1 \%)$ \\
\hline Daily injection & $3(75.0 \%)$ & $1(100 \%)$ \\
\hline Most commonly injected Heroine & $3(100 \%)$ & $1(100 \%)$ \\
\hline Shared needle or syringe & $3(75.0 \%)$ & $0(0.0 \%)$ \\
\hline Smoking daily, current & $50(87.7 \%)$ & $18(78.3 \%$ \\
\hline Alcohol use, ever & $10(18.9 \%)$ & $5(23.8 \%)$ \\
\hline \multicolumn{3}{|l|}{ Opioid agonist therapy (OAT) } \\
\hline Current & $29(55.8 \%)$ & $10(50.0 \%$ \\
\hline History, not current & $17(32.7 \%)$ & $7(35.0 \%)$ \\
\hline Never & $6(11.5 \%)$ & $3(15.0 \%)$ \\
\hline HCV knowledge $^{\dagger}$ & $4(6.7 \%)$ & $2(8.7 \%)$ \\
\hline HCV screening, ever & $10(16.7 \%)$ & $4(17.4 \%)$ \\
\hline HCV treatment uptake, ever & $3(5.0 \%)$ & $1(5.3 \%)$ \\
\hline Willingness to receive $\mathrm{HCV}$ treatment & $53(93.0 \%)$ & $19(90.5 \%$ \\
\hline
\end{tabular}

${ }^{\dagger}$ Answered three out of five questions correctly

\section{Drug use patterns}

The median age at first drug use was 18 (IQR 15-22 years), and the majority had a history of use in the last six months (67\%). From people who reported drug use in the previous month $(42 \%, n=24 / 57), 79 \%$ had used daily, most commonly Heroine and/or Methamphetamine (75\%). Overall, 48\% (28/59) had a history of injection; the median age at first injection was 20 (IQR $18-25$ years), $25 \%(n=7 / 28)$ had injected within the last six months and $14 \%(n=4 / 28)$ within the previous month. From people with recent injection (past month), the majority had daily injection (75\%), all Heroine $(100 \%)$, and had shared needles or syringes (75\%). People who attended SVR appointments were less likely to had injected within the last six months (9\% vs. $25 \%$, among those with history of injection) and shared needles or syringes ( $0 \%$ vs. $75 \%$, among those with injection in the previous month), compared to all patients (Table 2). 


\section{History of $\mathrm{HCV}$ care and knowledge}

History of HCV screening (antibody testing) and treatment uptake was $17 \%(n=10 / 60)$ and $5 \%(n=3 / 60)$, respectively. Out of five questions around HCV knowledge, $7 \%(n=4 / 60)$ answered three or more questions accurately. The majority had a strong willingness to receive HCV treatment $(93 \%, n=53 / 57$ ) (Table 2).

\section{HCV treatment and linkage to care}

One patient did not meet the criteria for treatment in prison due to concurrent HIV antiretroviral therapy. From 116 patients who were eligible for initiating treatment-all were candidates for a 12 -week DAA therapy $-24 \%(n=28)$ were released and $72 \%(n=83)$ initiated treatment in prison, including one individual who was released before treatment uptake and reincarcerated. Information on the treatment status of 5 other patients remains unknown.

From patients who received treatment in prison, $81 \%$ $(n=67 / 83)$ completed their course on-site and the rest were released. From those who were released during treatment, $63 \%(n=10 / 16)$ were followed by the network, and the majority completed treatment $(90 \%, n=9 / 10)$. Among patients released before treatment initiation, 71\% ( $n=20 / 28$ ) were linked to HCV care in the network, and the remaining were lost to follow-up. Among those who initiated treatment in the network, $60 \%(n=12 / 20)$ completed and the rest discontinued treatment for unspecified reasons. Therefore, among total petients who were released before or during treatment, $68 \%(n=30 / 44)$ were successfully followed and linked to care in the community and $70 \%(n=21 / 30)$ completed treatment (Fig. 1$)$.

Overall, a total number of 103 patients initiated treatment in prison or network, resulting in a treatment uptake of $89 \%(n=103 / 116)$. From this proportion, $85 \%$ $(n=88 / 103)$ completed treatment in prison or network. Forty-three percent $(n=38 / 88)$ of patients who had completed treatment were available for SVR assessment, who all had cured. People who initiated treatment in the community had a higher ITT SVR compared to those who

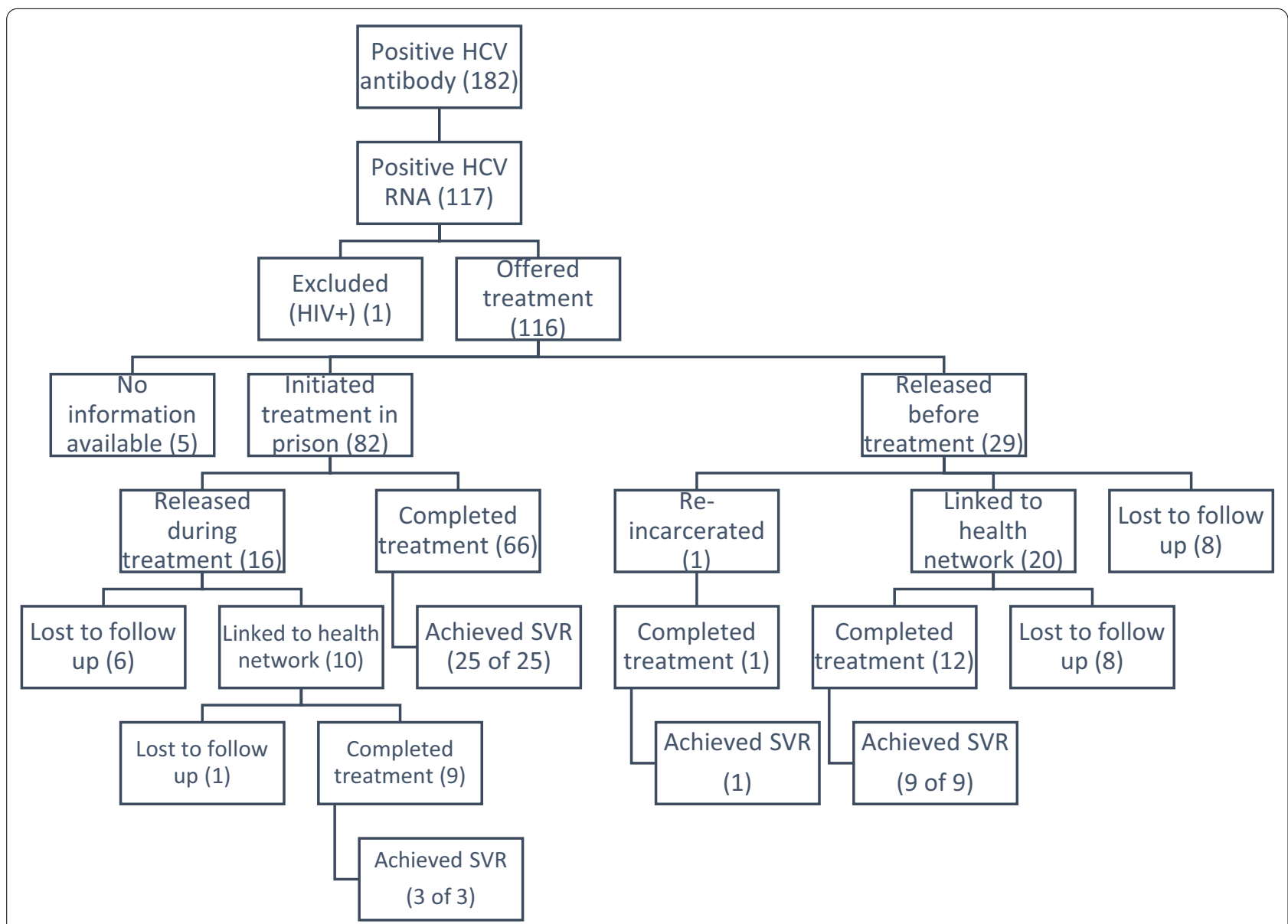

Fig. 1 Schematic view of HCV care cascade among Karaj prison participants. SVR: Sustained virological response 12 weeks post-treatment (among those who were tested) 
initiated in prison $[45 \%(n=9 / 20)$ vs. $35 \%(n=29 / 83)]$. Similarly, mITT SVR for patients who completed treatment in the community was higher compared to those who completed in prison $[57 \%(n=12 / 21)$ vs. $39 \%$ $(n=26 / 67)]$ (Fig. 2).

\section{Discussion}

To our knowledge, this is the first study that evaluates the impact of an $\mathrm{HCV}$ care program among newly admitted inmates in Iran, and one of the first studies that investigate the post-release engagement with $\mathrm{HCV}$ care worldwide. The prevalence of HCV antibody in this study was lower than the national estimations within prisons $(5.2 \%$ vs. $8 \%$ to $28 \%)[28,29]$, which may indicate the lower $\mathrm{HCV}$ infection rate among new inmates to the entire prison population. The overall engagement in treatment with $89 \%$ uptake and $85 \%$ completion rate was high, indicating the feasibility of $\mathrm{HCV}$ interventions among people in custody. The majority of patients who were released before or during treatment were linked to care (68\%) and completed treatment (70\%) in community. In comparison with retrospective studies that showed 10 to $25 \%$ linkage to HCV care after release [11, 12,30], these findings and encouraging cure rates in our study indicate that $\mathrm{HCV}$ programs can be strengthened remarkably by accurate post-release patient navigation.

\section{$\mathrm{HCV}$ testing and treatment history}

One-sixth of patients with available data had a history of testing, and only 5\% had received treatment, indicating the missed opportunities for $\mathrm{HCV}$ care in correctional settings. These low rates are comparable to previous reports from Iran as well as several highincome countries [12, 31, 32]. According to a 2020 report, among people incarcerated in US prisons, only $3 \%$ have access to HCV treatment, which underlines the necessity of escalating prison-based screening and linkage to care programs [33]. Although general knowledge around $\mathrm{HCV}$ infection was extremely poor, willingness to initiate treatment was promising; educational initiatives during imprisonment are highly recommended and may persuade people to seek their infection status post-release.

\section{$\mathrm{HCV}$ prevalence and risk behaviors}

The prevalence of HCV RNA among new inmates in this prison was slightly lower than our previous study (3.4 vs. $4.8 \%$ ), which had been estimated among both new inmates and residents in Northern Iran [32]. Despite the other Iranian reports, genotype 3a was more frequent than 1a in our study population [34]. Drug-related charges were common among all patients, and the majority had high-risk friendship networks or household members. Indicators of socioeconomic marginalization and risk behaviors in the previous month were less commonly seen among people who attended SVR assessment. Combined harm reduction services, including social support and stable housing, together with expanded opioid agonist therapy (OAT) programs, are crucial to control HCV epidemic in Iran and other countries $[35,36]$.

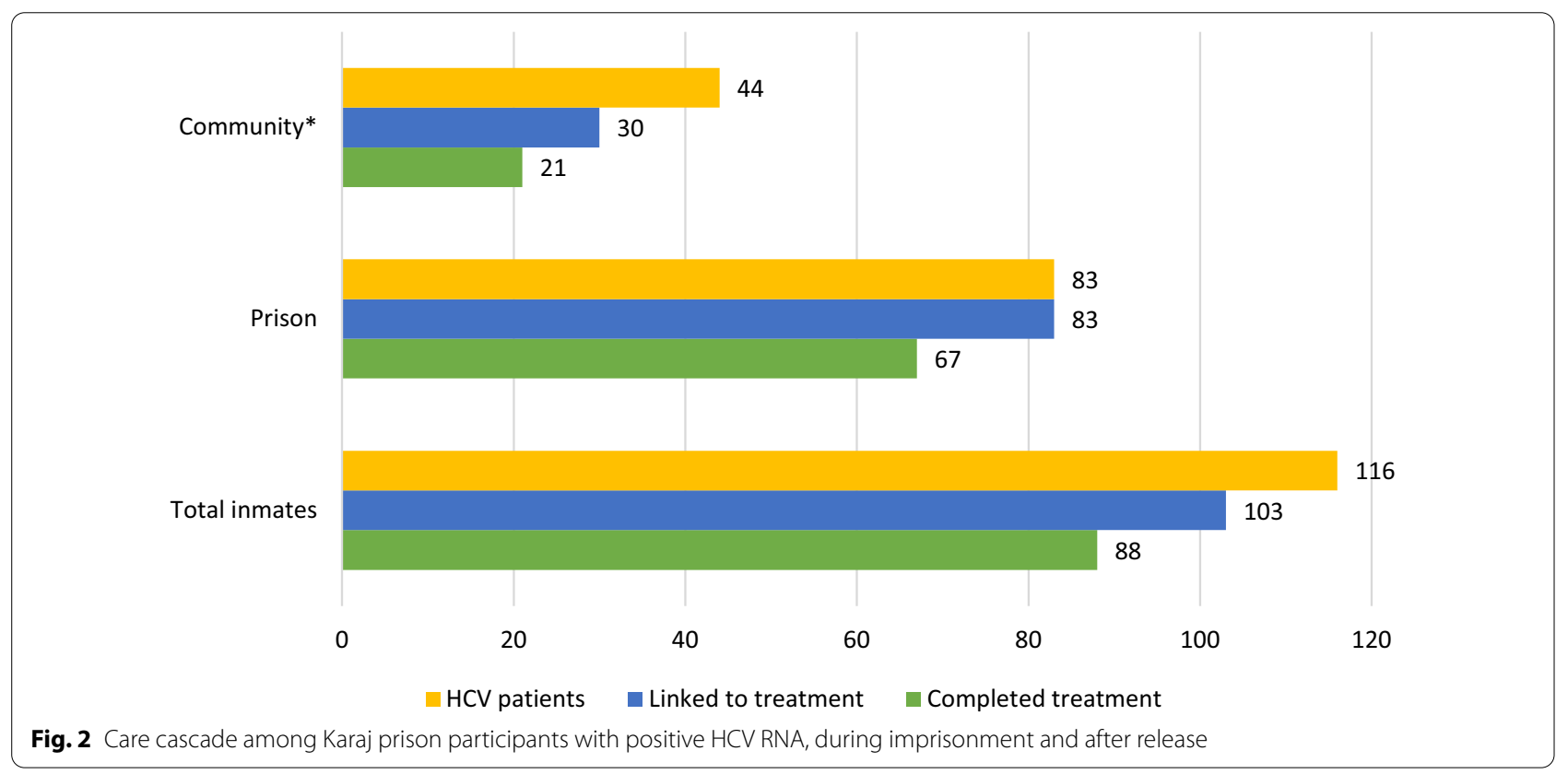




\section{HCV treatment uptake and completion}

Evidence surrounding prison-based $\mathrm{HCV}$ care interventions in the DAA era is scarce [37]. High treatment uptake and completion achieved in our study underlines great willingness towards treatment among people with $\mathrm{HCV}$ in prisons; these outcomes are comparable with another DAA-based prison study from Italy [38]. However, due to the heterogeneity of correctional settings and release patterns, effective intervention in a single prison may not be applicable in another. The median length of stay ranges from less than $48 \mathrm{~h}$ in jails to long-term housings in prisons, which highlights the necessity of adopting different healthcare strategies [39]. According to a US study, people who were released on parole were more likely to fill an antiretroviral therapy prescription than those with a standard release [40]. Thus, HCV programs should be tailored to the peculiar characteristics of the environment in which they are introduced [32, 39].

\section{HCV treatment outcomes}

Previous DAA-based studies have observed high cure rates among current and former prison inmates that are consistent with our results, such as a recent report from New South Wales (NSW) (ITT 57\%, mITT 92\%). The lower ITT SVR in this study (42\%) compared to the NSW can be explained by our two-fold higher release rates [41]. Similarly, although Pontali et al. have reported a higher ITT SVR (91\%) in an Italian prison, only $6 \%$ of their patients discontinued treatment due to release. In a Scottish research, SVR assessment showed similar results for people who initiated treatment in community and prison (63\% vs. 61\%) [42], and a higher response was observed among people who were not released or transferred, compared to those who were released during treatment (75\% vs. 45\%). We observed slightly better ITT outcomes for those who commenced therapy in the community than prison ( $45 \%$ vs. $35 \%$ ), which can be partly explained by a higher likelihood of adherence to treatment for people who are reached by the health networks after community return, compared to all released inmates. The ITT SVR among former inmates who initiated treatment in community was similar to a study from New York City jails ( $45 \%$ vs. $41 \%$ ); however, mITT SVR in our study was higher than their observed cure rates (57\% vs. 47\%) [15]. This difference may suggest a lower risk of reinfection or treatment failure in the Iranian community compared to the USA. These comparisons highlight the significant impact of release patterns on treatment response assessment and its interpretations in different settings, which could incorporate into a better prison- and communitybased HCV planning.

\section{Post-release HCV care}

There is a growing body of evidence on successful transitional programs to engage patients with healthcare services after release-mainly conducted by communitybased providers and NGOs-ranging from reminder calls to intensive case management [43]. Three studies from the USA have reported that only one-quarter of patients who returned to the community were linked to HCV care after incarceration $[15,30,44]$. However, we showed that more than two-thirds of patients could be linked to care following release, highlighting the critical role of active patient navigation in engaging patients with post-release care. The period of leaving incarceration is a particularly vulnerable time and many people may not receive sufficient long-term support during this period, which may lead to poor health outcomes, including treatment failure and reinfection [45]. Retention in treatment is also essential to prevent the risk of developing drug resistance [46]. Due to the similar competing priorities, factors that are considered as facilitators among people with HIV can be applied to the formerly incarcerated population with $\mathrm{HCV}$ to obtain synergistic effects. These include treatment for substance use and mental disorders, transportation assistance, offer drug-free transitional housing, and peer support $[11,22,47]$. Unfortunately, we were not able to provide such facilities in our study due to budget limitations.

\section{Limitations}

The main limitation of this work was the lack of close observation on the study procedures. To provide realworld information, we aimed to assign the entire work to prison staff and community providers, which resulted in some shortcomings in patient navigation and data collection, including the loss of several medical records. Some staff changes in prison interrupted our data collection process, and tracking down all questionnaires was impossible due to peculiar restrictions of the prison environment. Consistent with the WHO report on Prisons and Health, the penitentiary healthcare system should work in close collaboration with community providers to ensure that treatment is not interrupted when people enter or leave prison and also transferred within the justice system [46]. As we only recruited newly admitted inmates, the interpretation of our results for prison residents should be with caution. Besides, women were underrepresented in this study.

\section{Conclusions}

This work supports the feasibility of successful integrated HCV care models in custodial settings, strengthened significantly by post-release interventions. Establishing a multidisciplinary program through the 
collaboration of community and prison healthcare systems could promote health outcomes. A comprehensive approach should include appropriate discharge planning, increased referral resources, and patient navigation to encourage adherence to treatment among people who cycle through custody. More robust care models incorporating a variety of supportive services and risk reduction measures are needed to guarantee continuity of HCV care, and future studies should investigate the predictors of engagement with treatment and virological cure following release into the community.

\begin{abstract}
Abbreviations
APRI: AST to platelet ratio index; AST: Aspartate aminotransferase; DAA: Direct-acting antiviral; DHN: District health network; DOT: Directly observed therapy; ELISA: Enzyme-linked immunosorbent assay; HCV: Hepatitis C virus; HIV: Human immunodeficiency virus; IQR: Interquartile range; ITT: Intentionto-treat: mITT: Modified intention-to-treat: MMT: Methadone maintenance treatment; PWID: People who inject drugs; RDT: Rapid diagnostic test; RT-PCR: Reverse transcription-polymerase chain reaction; SVR: Sustained virological response; WHO: World Health Organization.
\end{abstract}

\section{Acknowledgements}

The authors would like to acknowledge the Karaj Central Prison staff and the Alborz district health network for their valuable contributions, and all prison inmates for their participation in this work.

\section{Authors' contributions}

SH drafted the manuscript. HS and SMA provided critical feedback and were major contributors to revising the manuscript. HP and SM conceived the original idea and designed the project. BT, MT, RA, and FH conducted the study and were involved in data collection. RM, MMG, and RR supervised the work. BA processed the data and performed the analysis. MS and FA provided insight into the interpretation of the results. All authors read and approved the final manuscript.

\section{Funding}

None.

\section{Availability of data and materials}

The datasets used and/or analyzed during the current study are available from the corresponding author on reasonable request.

\section{Ethics approval and consent to participate}

The review board of the Digestive Diseases Research Institute of Tehran University of Medical Sciences approved the research protocol. All participants provided written informed consent.

\section{Consent for publication}

Not applicable.

\section{Competing interests}

Shahin Merat and Hossein Poustchi own stocks and shares in Rojan Pharma.

\footnotetext{
Author details

${ }^{1}$ Liver and Pancreatobiliary Diseases Research Center, Digestive Disease Research Institute, Shariati Hospital, Tehran University of Medical Sciences, N. Kargar St., 14117 Tehran, Iran. ${ }^{2}$ Middle East Liver Diseases (MELD) Center, Tehran, Iran. ${ }^{3}$ Section of Genetics, International Agency for Research on Cancer, Lyon, France. ${ }^{4}$ Centre for Communicable Diseases Control, Ministry of Health and Medical Education, Tehran, Iran. ${ }^{5}$ Health and Treatment Directorate of Prisons and Security and Corrective Measures Organization, Tehran, Iran.
}

Received: 4 August 2020 Accepted: 13 October 2020

Published online: 20 October 2020

\section{References}

1. Hajarizadeh B, Grebely J, Matthews GV, Martinello M, Dore GJ. The path towards hepatitis $C$ elimination in Australia following universal access to interferon-free treatments. J Hepatol. 2017;66(1):S291-2.

2. Zelenev A, Li J, Mazhnaya A, Basu S, Altice FL. Hepatitis C virus treatment as prevention in an extended network of people who inject drugs in the USA: a modelling study. Lancet Infect Dis. 2018;18(2):215-24.

3. Stone J, Martin NK, Hickman M, Hutchinson SJ, Aspinall E, Taylor A, et al. Modelling the impact of incarceration and prison-based hepatitis $C$ virus (HCV) treatment on $\mathrm{HCV}$ transmission among people who inject drugs in Scotland. Addiction. 2017;112(7):1302-14.

4. Moazen B, Saeedi Moghaddam S, Silbernagl MA, Lotfizadeh M, Bosworth RJ, Alammehrjerdi Z, et al. Prevalence of drug injection, sexual activity, tattooing, and piercing among prison inmates. Epidemiol Rev. 2018;40(1):58-69.

5. Dolan K, Wirtz AL, Moazen B, Ndeffo-mbah M, Galvani A, Kinner SA, et al. Global burden of HIV, viral hepatitis, and tuberculosis in prisoners and detainees. Lancet. 2016;388(10049):1089-102.

6. Organization WH. Global hepatitis report 2017. Geneva: World Health Organization; 2017.n

7. Bartlett SR, Fox P, Cabatingan H, Jaros A, Gorton C, Lewis R, et al. Demonstration of near-elimination of hepatitis $C$ virus among a prison population: the lotus glen correctional centre hepatitis $C$ treatment project. Clin Infect Dis. 2018;67(3):460-3.n

8. Ranieri R, Starnini G, Carbonara S, Pontali E, Leo G, Romano A, et al. Management of $\mathrm{HCV}$ infection in the penitentiary setting in the direct-acting antivirals era: practical recommendations from an expert panel. Infection. 2017:45(2):131-8.nn

9. Crowley D, Cullen W, Lambert JS, Van Hout MC. Competing priorities and second chances: a qualitative exploration of prisoners'journeys through the Hepatitis C continuum of care. PLoS ONE. 2019;14(9):e0222186.n

10. Klein SJ, Wright LN, Birkhead GS, Mojica BA, Klopf LC, Klein LA, et al. Promoting HCV treatment completion for prison inmates: New York State's hepatitis C continuity program. Public Health Rep. 2007;122(Suppl 2):83-8.nnn

11. Hawks L, Norton BL, Cunningham CO, Fox AD. The Hepatitis C virus treatment cascade at an urban postincarceration transitions clinic. J Viral Hepat. 2016;23(6):473-8.nn

12. Hochstatter KR, Stockman LJ, Holzmacher R, Greer J, Seal DW, Taylor $\mathrm{QA}$, et al. The continuum of hepatitis $C$ care for criminal justice involved adults in the DAA era: a retrospective cohort study demonstrating limited treatment uptake and inconsistent linkage to community-based care. Health Just. 2017:5(1):10.n

13. Cocoros N, Nettle E, Church D, Bourassa L, Sherwin V, Cranston K, et al. Screening for Hepatitis $C$ as a Prevention Enhancement (SHAPE) for HIV: an integration pilot initiative in a Massachusetts County correctional facility. Public Health Rep. 2014;129(Suppl 1):5-11.nnn

14. Sullivan E, Ward S, Zeki R, Wayland S, Sherwood J, Wang A, et al. Recidivism, health and social functioning following release to the community of NSW prisoners with problematic drug use: study protocol of the population-based retrospective cohort study on the evaluation of the Connections Program. BMJ Open. 2019;9(7):e030546.n

15. Akiyama MJ, Columbus D, MacDonald R, Jordan AO, Schwartz J, Litwin $\mathrm{AH}$, et al. Linkage to hepatitis $\mathrm{C}$ care after incarceration in jail: a prospective, single arm clinical trial. BMC Infect Dis. 2019;19(1):703.n

16. Begun AL, Early TJ, Hodge A. Mental health and substance abuse service engagement by men and women during community reentry following incarceration. Admin Policy Mental Health Mental Health Serv Res. 2016;43(2):207-18.

17. Binswanger IA, Nowels C, Corsi KF, Long J, Booth RE, Kutner J, et al. "From the prison door right to the sidewalk, everything went downhill", A qualitative study of the health experiences of recently released inmates. Int J Law Psychiatry. 2011;34(4):249-55.n

18. Van Dorn RA, Desmarais SL, Rade CB, Burris EN, Cuddeback GS, Johnson $\mathrm{KL}$, et al. Jail-to-community treatment continuum for adults with 
co-occurring substance use and mental disorders: study protocol for a pilot randomized controlled trial. Trials. 2017;18(1):365.n

19. Nations U. Additional Guidance on Aftercare and Reintegration Programmes for Violent Extremist Offenders. 2014.

20. Myers JJ, Kang Dufour M-S, Koester KA, Morewitz M, Packard R, Monico Klein K, et al. The effect of patient navigation on the likelihood of engagement in clinical care for HIV-infected individuals leaving jail. Am J Public Health. 2018;108(3):385-92.n

21. Loeliger KB, Altice FL, Desai MM, Ciarleglio MM, Gallagher C, Meyer JP. Predictors of linkage to HIV care and viral suppression after release from jails and prisons: a retrospective cohort study. Lancet HIV. 2018;5(2):e96-106.n

22. Yanes-Lane M, Dussault C, Linthwaite B, Cox J, Klein MB, Sebastiani G, et al. Using the barriers and facilitators to linkage to HIV care to inform hepatitis $\mathrm{C}$ virus (HCV) linkage to care strategies for people released from prison: findings from a systematic review. J Viral Hepat. 2020;27(2):205-20.

23. Kouyoumdjian FG, Schuler A, Mclsaac KE, Pivnick L, Matheson Fl, Brown G, et al. Using a Delphi process to define priorities for prison health research in Canada. BMJ Open. 2016;6(1):e010125.nnn

24. Kronfli N, Linthwaite B, Kouyoumdjian F, Klein MB, Lebouché B, Sebastiani $G$, et al. Interventions to increase testing, linkage to care and treatment of hepatitis $\mathrm{C}$ virus (HCV) infection among people in prisons: a systematic review. Int J Drug Policy. 2018;57:95-103.

25. Zamani S, Farnia M, Torknejad A, Alaei BA, Gholizadeh M, Kasraee F, et al. Patterns of drug use and HIV-related risk behaviors among incarcerated people in a prison in Iran. J Urban Health. 2010;87(4):603-16.nn

26. Kadjbaf D, Keshvari M, Alavian SM, Pouryasin A, Behnava B, Salimi S, et al. The prevalence of hepatitis $C$ virus core amino acid 70 substitution and genotypes of polymorphisms near the IFNL3 gene in Iranian patients with chronic hepatitis C. Hepat Mon. 2016;16(6):e37011.nn

27. Sharafi H, Poustchi H, Azimian F, Tamadoni B, Ramezani R, Gouya MM, et al. Performance of a rapid diagnostic test for screening of hepatitis $C$ in a real-life prison setting. J Clin Virol. 2019;113:20-3.nn

28. Moradi G, Gouya M-M, Azimizan Zavareh F, Mohamadi Bolbanabad A, Darvishi S, Aghasadeghi MR, et al. Prevalence and risk factors for HBV and $\mathrm{HCV}$ in prisoners in Iran: a national bio-behavioural surveillance survey in 2015. Trop Med Int Health. 2018;23(6):641-9.nn

29. Behzadifar M, Gorji HA, Rezapour A, Bragazzi NL. Prevalence of hepatitis $C$ virus infection among prisoners in Iran: a systematic review and metaanalysis. Harm Reduct J. 2018;15(1):24.n

30. Beckwith CG, Kurth AE, Bazerman LB, Patry EJ, Cates A, Tran L, et al. A pilot study of rapid hepatitis $C$ virus testing in the Rhode Island Department of Corrections. J Public Health (Oxf). 2016;38(1):130-7.n

31. Young S, Wood E, Milloy MJ, DeBeck K, Dobrer S, Nosova E, et al. Hepatitis $C$ cascade of care among people who inject drugs in Vancouver. Canada Subst Abus. 2018;39(4):461-8.n

32. Hariri S, Sharafkhah M, Alavi M, Roshandel G, Fazel A, Amiriani T, et al. A simple risk-based strategy for hepatitis $C$ virus screening among incarcerated people in a low- to middle-income setting. Harm Reduct J. 2020;17(1):56.n

33. Correctional institutions are a critical intervention point for hepatitis $C$ elimination. O'Neill Institute for National and Global Health Law. March 2020. https://oneill.law.georgetown.edu/wp-content/uploads/HepC_ Corrections_FINAL 03272020.pdf.

34. Mahmud S, Akbarzadeh V, Abu-Raddad LJ. The epidemiology of hepatitis $C$ virus in Iran: Systematic review and meta-analyses. Sci Rep. 2018;8(1):150.nn
35. Platt L, Minozzi S, Reed J, Vickerman P, Hagan H, French C, et al. Needle and syringe programmes and opioid substitution therapy for preventing HCV transmission among people who inject drugs: findings from a Cochrane review and meta-analysis. Addiction (Abingdon, England). 2018;113(3):545-63.

36. Scherz N, Bruggmann P, Brunner N. Direct-acting antiviral therapy for hepatitis $\mathrm{C}$ infection among people receiving opioid agonist treatment or heroin assisted treatment. Int J Drug Policy. 2018;62:74-7.nn

37. Vroling H, Oordt-Speets AM, Madeddu G, Babudieri S, Monarca R, O'Moore E, et al. A systematic review on models of care effectiveness and barriers to Hepatitis $\mathrm{C}$ treatment in prison settings in the EU/EEA. J Viral Hepat. 2018;25(12):1406-22.n

38. Pontali E, Fiore V, lalungo AM, Ranieri R, Mollaretti O, Barbarini G, et al. Treatment with direct-acting antivirals in a multicenter cohort of HCVinfected inmates in Italy. Int J Drug Policy. 2018;59:50-3.n

39. Spaulding AC, Perez SD, Seals RM, Hallman MA, Kavasery R, Weiss PS. Diversity of release patterns for jail detainees: implications for public health interventions. Am J Public Health. 2011;101(Suppl 1):S347-52.n

40. Baillargeon J, Giordano TP, Rich JD, Wu ZH, Wells K, Pollock BH, et al. Accessing antiretroviral therapy following release from prison. JAMA. 2009;301(8):848-57.n

41. Overton K, Clegg J, Pekin F, Wood J, McGrath C, Lloyd A, et al. Outcomes of a nurse-led model of care for hepatitis $C$ assessment and treatment with direct-acting antivirals in the custodial setting. Int J Drug Policy. 2019;72:123-8.n

42. Aspinall EJ, Mitchell W, Schofield J, Cairns A, Lamond S, Bramley P, et al. A matched comparison study of hepatitis $C$ treatment outcomes in the prison and community setting, and an analysis of the impact of prison release or transfer during therapy. J Viral Hepat. 2016;23(12):1009-16.

43. Hu C, Jurgutis J, Edwards D, O'Shea T, Regenstreif L, Bodkin C, et al. "When you first walk out the gates... where do [you] go?": Barriers and opportunities to achieving continuity of health care at the time of release from a provincial jail in Ontario. PLOS ONE. 2020;15(4):e0231211.n

44. Schoenbachler BT, Smith BD, Seña AC, Hilton A, Bachman S, Lunda M, et al. Hepatitis C Virus testing and linkage to care in North Carolina and South Carolina Jails, 2012-2014. Public Health Rep. 2016;131 (Suppl 2):98-104.n

45. Kendall S, Redshaw S, Ward S, Wayland S, Sullivan E. Systematic review of qualitative evaluations of reentry programs addressing problematic drug use and mental health disorders amongst people transitioning from prison to communities. Health Justice. 2018;6(1):4.n

46. (WHO) WHO. Prisons and Health. 2020

47. Teixeira PA, Jordan AO, Zaller N, Shah D, Venters H. Health outcomes for HIV-infected persons released from the New York City jail system with a transitional care-coordination plan. Am J Public Health. 2015;105(2):351-7.nn

\section{Publisher's Note}

Springer Nature remains neutral with regard to jurisdictional claims in published maps and institutional affiliations.

\footnotetext{
Ready to submit your research? Choose BMC and benefit from:

- fast, convenient online submission

- thorough peer review by experienced researchers in your field

- rapid publication on acceptance

- support for research data, including large and complex data types

- gold Open Access which fosters wider collaboration and increased citations

- maximum visibility for your research: over $100 \mathrm{M}$ website views per year
}

At $\mathrm{BMC}$, research is always in progress.

Learn more biomedcentral.com/submissions 